\title{
The Evolution of Physical Oceanography in the Last Hundred Years
}

\author{
Walter Munk \\ Scripps Institution of Oceanography - La Jolla, California USA
}

\begin{abstract}
The last hundred years have seen a revolution in our understanding of ocean processes. I have selected a subset of seven topics. Technological developments generally led (rather than followed) new ideas. The advent of satellite remote sensing led to global sampling with adequate spatial sampling density (two quite different achievements, both of enormous consequence). Computers permitted the timely reduction of very large datasets of disparate observations into digestible displays, including also meaningful estimates of the uncertainties of the measured fields. Underlying all these development is a century of transition from grossly inadequate expeditionary sampling to an appreciation of a rational sampling strategy.
\end{abstract}

At the opening ceremony of the Lisbon 1998 EXPO, David Halpern assigned me to speak on "Oceanography Before Satellites" and allocated five minutes to do so. Yes, there was oceanography before satellites (Figure 1). I now have a generous eight pages to review the last hundred years. I will describe events the way I remember them; if in fact they were different, they ought to have been this way.

The dawn of the century found physical oceanographers in an expedition mode taking Nansen-casts and interpreting the observations in terms of a steadystate circulation in exact geostrophic balance. The following quote may sound vaguely familiar: "Oceanography... has undergone a rather rapid development during the last decades tending from a more descriptive science towards working according to exact mathematical-physical principles" (written by Albert Defant $^{1}$ during the closing days of the Meteor Expedition 1925-27.)

Defant was referring to the general principles of Physikalische Hydrodynamik ${ }^{2}$ developed in twenty five years under the leadership of V. Bjerknes, built on the work of his father C.A. Bjerknes (and continued by his son J. Bjerknes). At one time or another the "Bergen

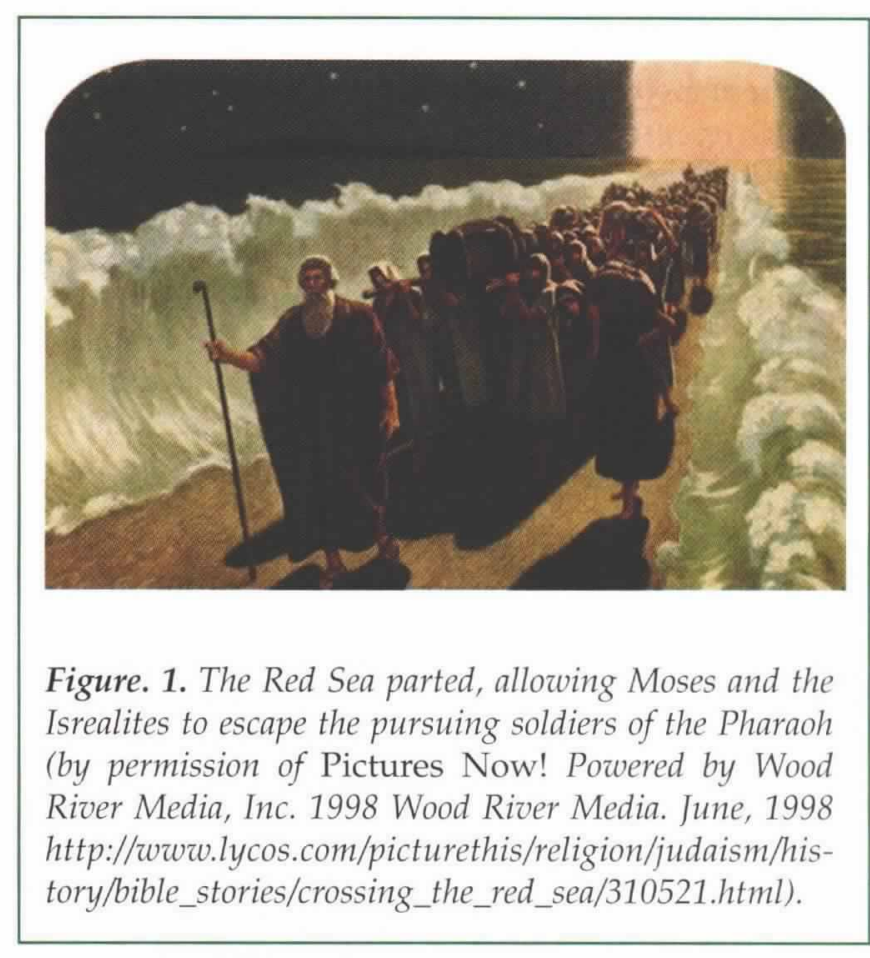

School" included J.W. Sandstöm, T. Bergeron, H. Solberg, W. Ekman, H.U. Sverdrup and C.G. Rossby. Sverdrup (my teacher) turned down a permanent position in Bergen (an unheard-of act of independence) for adventure in the Arctic and a career centered on measurement and analysis.

Physikalische Hydrodynamik differs from "pure" hydrodynamics in three important ways: stratification, rotation and turbulence. Stratification was handled by multi-layered (rather than continuously stratified) media, and there are only two brief references to turbulence; connection to reality was handled by arbitrarily

'Albert Defant 1961, Physical Oceanography, Pergamon Press, New York, translated from Dynamische Oceanographie, J.Springer, Berlin 1929. 
amplifying the coefficients of molecular viscosity and diffusivity. This started on a day in 1900 when Nansen shared his intuition about wind-driven currents with Bjerknes; the student Ekman was called into the discussion and produced the theory of the Ekman spiral that very evening. But it took some hundred years until the coherent structure of a spiral could be unambiguously identified in the "noisy" layers of the upper ocean".

I am not aware of any major advances until midcentury. To illustrate what has happened since, I have selected seven topics. Someone else would have selected seven different topics. And for every achievement here noted, three have been left out. This is no way to make friends.

\section{Coming to Terms with Noisy Processes}

Following the practice of a successful tide prediction, waves and other noisy ocean processes had been fitted by a sum of terms of discrete period and phase. At the time there was not a single oceanographer familiar with the representation of random-phase processes by a continuous distribution of spectral energy (the acoustic and optical community understood it perfectly well).

Methods for predicting ocean surface waves were developed in the early 1940s in response to military needs. George Deacon (later Sir George) assembled a remarkable array of talent within the British Admiralty (Barber, Longuet-Higgins, Ursell, among others). Norman Barber spun a 20-minute wave record around the periphery of a rapidly spinning wheel; as the wheel slowed under friction, the recorded output of the greatly stepped up frequencies was played through an R-C filter to yield the band-passed energy at successively lower frequencies. Later on John Tukey took me under his wing to compute the wave spectra with the early punch-card computers, using a digital paradigm he had developed.

Two basic theories for the transfer of energy from wind to waves were published by Miles and by Phillips in 1957, and Phillips introduced his celebrated $\mathrm{k}^{-1}$ equilibrium spectrum in 1958 (this follows trivially from dimensional considerations, but like Ekmna's "one-night'er" it has been subject to experimental verification for the remainder of the century). In 1963 Hasselmann clarified the crucial role played by the non-linear energy transfer from the short and long components to the energetic central spectrum. The subject has now advanced to a point where wave predic- tion is routinely used in a wide range of human activities. Measuring the global wave field by synthetic aperture radar (SAR) satellites is in progress. I expect that in future the de-convolution of the measured wave field will provide useful statistics about the wind field (rather than the other way around).

The resulting conceptual advance in the treatment of noisy processes had far-reaching consequences: meaningful estimates of the coherence (or lack thereof) between two noisy processes; proper estimates of signal-to-noise ratios and the development of realistic sampling strategies. Our community became painfully aware of the fact that for a hundred years we had catastrophically undersampled the oceans!

\section{Destroying the Theology of a Steady
Circulation}

By the turn of the $20^{\text {th }}$ century the major current systems (Gulf Stream, Kuroshio, Brazil Current...) had been discovered. In the 1960s, Cromwell, Knauss and Montgomery reported on the Equatorial Undercurrent, the last major current system missing from the lexicon of oceanography'.

Oceanographers were just coming to terms with Sverdrup's 1947 solution for the mid-ocean circulation in response to wind torquing, and to Stommel's 1948 explanation of the intensification of currents along west boundaries (e.g. Gulf Stream). These epoch-making solutions are simple enough mathematically to be "one-night'ers" (in the Ekman tradition); in fact, Sverdrup derived his solution from an examination cross-equatorial hydrographic profiles and Stommel from noting the exponential-like behavior of numerical solutions.

The basic elements of the deep (thermohaline) ocean circulation were known in Sverdrup's time. (He mapped global volume fluxes in units of million cubic meters/second, now known as sverdrups.) Starting in 1960, Stommel and Arons provided a dynamical (though highly idealized) framework of deep water transport from higher to lower latitudes along western boundaries, and communication between the ocean basins accomplished via the Antarctic Circumpolar Current. Broecker's subsequent visualization called "the great conveyor belt" has enjoyed popular support because of its vividness, and support by the chemists because of its simplicity.

The fashion at the time was to map the measured

\footnotetext{
See T.K.Chereskin 1995, Direct evidence for an Ekman balance in the California Current, J. Geoph. Res. 109: 18,261-269. The vertical spiral dimen sion is controlled by numerical choice for the eddy viscosity, quite arbitrary in Ekman's days, but eventually related by Weller and his associates to Langmuir circulation. Ekman himself had developed the "Ekman current meter" to search for the spiral (Ekman V.W. and B. Helland-Hansen 1931, Measurement of ocean currents; experiments in the North Atlantic. Kungliga Fysiografiska Sällskapets $i$ Lind Förhandlingar, 1:1-7, 265) but despaired about the lack of resemblance between measurements at small vertical separations. But this is the expected result for broad-band process es (coherence distance is the reciprocal of the wavenumber bandwidth). I believe (from discussions with Ekman in 1949) that this lack of coherence was the reason why Ekman postponed for 23 years (to his last paper one year before his death) the publication of "Results of a Cruise on Board the 'Armauer Hansen' in 1930 under the leadership of Björn Helland-Hansen (Ekman V.W. 1953, Geofysike Publikasjoner 19:1, 265).

The undercurrent was actually discovered in 1886 and then forgotten (Buchanan J.Y. 1888, The exploration of the Gulf of Guinea. Scottish Geographical Magazine 4: 177-200, 233-251).
} 
scalar fields of temperature and salinity, and to infer the current velocities by a joint application of the hydrostatic and geostrophic relations. A fundamental shortcoming is that this procedure gives only relative currents, and much effort has been expended to find the so-called "depth-of-no-motion", often identified (for no good reason) with the depth of minimum shear. The problem was solved in the 1970s by Stommel (with Schott, Behringer and Armi) in his work on the $\beta$-spiral, and later by Wunsch in his application of inverse methods.

A second shortcoming is that smooth scalar distributions do not necessarily call for smooth, steady current systems, the scalar fields being in a sense space and time integrals of the motion field. One has found smooth scalar fields in the presence of extremely complex float trajectories. But there was so much confidence in the method that the U.S. Navy issued current charts on pocket-handkerchiefs to WWII pilots in the Pacific so that, if downed, they could navigate the "known" surface currents towards the nearest islands. We now know that the downed flyers would have found the current charts useful only if they had been willing to integrate their drifting experience over a year or two.

The underlying theology was that of a steady ocean circulation: differences between stations were attributed to the difference in station position, not the difference in station time. It is ironic that progress on the problem of the depth-of-no-motion came about just as it was found that ocean currents were seriously time-dependent at all depths. We now know that more than $99 \%$ of the kinetic energy of ocean currents is associated with variable currents, the so-called mesoscale variability of roughly $100 \mathrm{~km}$ and 100 days. Incredible as it may seem, for one hundred years this dominant component of ocean circulation had slipped through the coarse grid of traditional samplings. Our concept of ocean currents has changed from something like $10 \pm 1 \mathrm{~cm} / \mathrm{s}$ to $1 \pm 10 \mathrm{~cm} / \mathrm{s}$.

This first century of oceanography, since the days of the Challenger Expedition in the 1870s, came to an abrupt end in the 1970s. The oceanographic community had been aware since the 1950s of the meandering of the Gulf Stream. If there was any doubt, the multiple ship operation CABOT (the first of its kind) under the leadership of Fritz Fuglister dramatically demonstrated the shedding of a cold-core eddy. At first it was thought that transients are confined to the regions of the western boundary currents. But the acoustic tracking of neutrally buoyant floats by Swallow (who cred- its Stommel for suggesting this idea) soon demonstrated that variability in space and time was the rule, not the exception (though more intense near the boundary currents). There was an urgent need for a systematic exploration of the ocean variability. The development of deep-ocean mooring technology provided such an opportunity, and the Mid- Ocean Dynamics Experiments (MODE) starting in 1973 under the leadership of Stommel and Robinson defined the parameters of variability. (The Russian oceanographer Brekhovskikh got there first, but failed to reach definitive results because of a high failure rate of current meters.) We now think of this mesoscale variability as the ocean weather, and the underlying circulation as the ocean climate (itself subject to slow variations). Climate came first, weather later; rather the opposite of what happened in meteorology.

\section{Discovering Micro Structure}

At the opposite end of the general circulation scale is the micro- (or dissipation) scale where energy is irreversibly converted into heat. We are talking about millimeters to centimeters; but just because the process scales are small does not mean the process is less important.

Oceanographers had been aware of microstructure since the early days of bathythermographs. Smoked glass slides often showed tiny step-wise structure in the temperature profiles; this was blamed on "stiction" and the instrument suitably repaired by banging it on the deck. Cox, Osborn and Gregg developed the instrumentation with the required vertical resolution and found typical pelagic diffusivities of $10^{-5} \mathrm{~m}^{2} / \mathrm{s}$, a thousand times the molecular values. Ledwell confirmed these values by in situ measurements of the diffusion of a dye patch. I have previously referred to the unfortunate habit of choosing eddy coefficients of arbitrary magnitude to fit the observations of the moment. Measurements of microstructure finally provided some insight into the relevant physical processes.

In this connection we need to mention two other important developments. In 1956 Stommel (with Arons and Blanchard) published a paper: "An oceanographical curiosity: the perpetual salt fountain". In a temperature-stable and salt-unstable stratification, a vertical hose, once primed, will forever pump up cold, salty (and nutrient-rich) deep water. Stern realized that this was associated with a fundamental instability (hose or no hose), and Turner developed this into the discipline of double-diffusive mixing.

The MEDOC experiment in 1969 (another Stommel 
brainchild) provided direct measurements of convective overturning. Prior to MEDOC there had been very little direct observational evidence for deep water formation.

\section{Resurrecting Tides}

Tides are the earliest application of oceanography to human activities. The subject has twice been declared dead, after Newton and after Laplace. When I applied for financial support in the 1960s to measure deep-sea tides I was told the subject has gone to bed with Victorian mathematicians. But this field has been revived by the computer revolution. In 1969 Pekeris and Accad solved the Laplace tide equation over a world ocean with realistic topography and boundaries. There was a need to compare the global computations with measurements in the open sea. Coastal tide gauges have been around for centuries, but the ability to measure deep sea tides did not come up till the early 1960s when pressure gauges could be dropped freely to the deep sea floor and subsequently recalled acoustically; about 350 pelagic stations have been occupied (mostly by Cartwright) in the 30 year window before satellite altimetry provided the means of truly global sampling.

Dissipation of the principal lunar tide is $2.50 \pm .05$ TWatts, very accurately derived from the measured rate of $3.82 \mathrm{~cm} / \mathrm{s}$ at which the moon moves away from the Earth. Satellite altimetry measurements (Ray, Mitchum and Egbert, among others) have shown that about one third of this is converted into internal (baroclinic) tidal energy. Oceanographers are inclined towards baroclinic processes, so this has raised a great deal of interest. Pinkel's HOME experiment now being conducted at the Hawaiian island chain hopefully will come up with a barotropic to baroclinic scattering budget.

None of this should come as a surprise. Otto Petterson in 1909 measured large internal tides in the Kattegat (and from these deduced a novel theory of climate). In 1930 Lek reported 60 meter high internal tides in Indonesian waters. All this had faded from memory until the signature of internal waves and tides showed up on satellite images.

Some, perhaps most, of the internal tide energy is available for mixing. There is enough energy there to account for all of the ocean mixing indicated by the microstructure measurements. Getting the mixing right is an essential requirement for modeling the oceanic equator-to-pole heat flux, perhaps the most basic of climate parameter. Once again tides have been saved from demise.

\section{Climate Is Back}

A first-order consideration is the equator-to-pole heat flux ( 3.7 PWatts across $24^{\circ} \mathrm{N}$ ) required to maintain the global heat balance. In 1942 Sverdrup estimated that the ocean contributed $10 \%$, and this was mostly in the wind-driven circulation. We now estimate that the ocean carries more than half the total flux, with com- parable contributions from the wind- and buoyancydriven circulations (the distinction is no longer very helpful). Quite a change!

Milankovitch long ago computed long-term variations in the orbital parameters of the Earth-sun-moon system, with characteristic periods near 20,000, 40,000 and 100,000 years. In a remarkable development pioneered by Imbrie, these periods have now been detected in the ocean sediment and glacial records. They provide important information concerning the atmosphere-ocean response to harmonic forcing.

Hasselmann pioneered an approach which in some sense is orthogonal to that of Milankovitch: a "random walk" of the climate state in response to random pulses associated with short-term "weather". Random walks are associated with large long-time departures from the mean; it remains to be determined whether the dramatic manifestations of climate variance associated with the Milankovitch orbital line spectrum exceed the Hasselmann random-walk continuum.

The coupled ocean-atmosphere system is capable of complex feedback systems. A number of those have been identified, starting in 1960 with J. Bjerknes' (son of V.) pioneering study of El Niño-Southern Oscillation (ENSO), a combined ocean (El Niño) and atmosphere (Southern Oscillation) phenomenology. El Niño has a recognizable linear component in a highly nonlinear equatorial dynamics: an equatorially-trapped wave moving eastward at a rate of order $0.1 \mathrm{~m} / \mathrm{s}$.

There has been significant progress in ENSO prediction. ENSO, the Pacific "decadal variation" and the North Atlantic Oscillation, account for a significant fraction of the ambient global variance.

Greenhouse warming has occupied center-stage (a "cottage industry" according to Revelle), largely because mankind can (and might) do something about this component of climate variability. The oceans are the principal reservoir for the storage of $\mathrm{CO}_{2}$, of heat and of ignorance. Model prediction now have error bars of the same order as the predicted mean change. There is urgent need for observational testing. The inevitable result will be an improved modeling and an increased understanding of ocean processes.

But I would urge some caution. Given that some of the underlying processes are not yet understood, given the slow rate of demonstrating new processes (remember the Ekman spiral), given the requirement of long time series for testing models, given that long time series take long times, we cannot expect to "solve" the climate problem in the next few decades.

\section{Age of Modeling}

Computer modeling has become a central ingredient in all our work. Prior to conducting any experiment it is now customary to model the expected processes and to test whether the proposed sampling is adequate. In reviewing some past experiments designed to answer certain questions one finds that the proposed measurements could not possibly have decided the issue with 
any reasonable degree of probability even if all measurements had worked (which is not always the case).

I am not a modeler, and the field is too important to be treated here by pontifications. But perhaps I may be permitted the remark that the modeling community enjoys two undue advantages over the sea-going community: a comfortable work environment and relatively low cost.

\section{The Technology Revolution}

More often than not new ideas have come out of new technology, rather than the other way around. High speed computers led to an explosion in the 1950s in every branch of physical oceanography (I have already listed a few examples). Readily available analysis of noisy records led at last to a sensible and reproducible description of surface waves, internal waves and numerous other ocean processes. It opened the door to objective analyses of extensive and diverse datasets and to matched field processing of ocean acoustic transmissions. The application of inverse theory to ocean measurements yielded an objective approach for estimating the validity of a given set of assumptions. In the past, oceanographers had found support for their favorite theory without such an objective assessment.

We have already referred to the revolution associated with the development of a deep sea mooring technology. A similar case can be made for drifters, particularly those with a programmed depth strategy, $z(t)$. Drifters have spearheaded a Lagrangian renaissance led by T. Rossby, D. Webb and R. Davis.

The oceans are a remarkably good propagator of sound (but not of electromagnetic energy), and this has played a profound role in ocean exploration starting with the acoustically located Swallow floats. The application of inverse methods has made possible the interpretation of a recorded acoustic transmission in terms of the properties of the intervening water column.

Satellites constitute the most important technology innovation in modern times. I consider the U.S./French altimetry satellite TOPEX/POSEIDON (fathered in the U.S. by Wunsch) the most successful ocean experiment of all times. Like other sea-going people, oceanographers are a conservative lot; many believe that research not conducted from vessels (sailing vessels in particular) is not oceanography. Oceanographers did not welcome satellites with open arms. John Apel came to Scripps and Woods Hole in 1970 to look for advice and support in planning SEASAT. He got neither. When mentioning that the SEASAT altimeter would measure dynamic height, a well-known oceanographer replied: "if you gave it to me, I would not know what to do with it" (Apel, personal communication, 1999). The statement ranks first among the contenders for THE WILLIAM LEIGHTON
JORDAN ESQ. AWARD of the Society of Subprofessional Oceanographers (SOSO) to be "... given annually to the Oceanographer who makes the most misleading contribution ..." (another Stommel invention).

We must not overlook low-tech developments. A U.S. patent for the O-ring was awarded to Niels Christensen in 1939. Until the mid-1960s we used to load our gear into numerous boxes and carry them aboard the vessels, only to find that a crucial item had been left ashore. I think Frank Snodgrass was the first to build portable laboratories with the equipment assembled and pre-tested. The portable laboratory is then brought aboard, ready for action. Decks of oceanographic vessels now provide bolt-downs 2 feet on center for securing the portable laboratories. In about the same period we learned how to drop unattached instruments to the relatively benign environment of the deep sea floor, later to be recalled acoustically. There was a psychological block to overcome; it is not easy to let go of a line from which hangs next year's budget of equipment.

\section{People Who Made a Difference}

The evolution from an expeditionary mode to a more systematic ocean monitoring is a hallmark of this century: pioneering examples are Bigelow's study of the Gulf of Maine and Sverdrup's initiation of a time series of the California Current System. Sverdrup, Johnson and Fleming's The Oceans is a benchmark against which the subsequent revolution in oceanography can be compared (Figure 2).

Woods Hole Director Bigelow and Scripps Director Sverdrup were succeeded by Iselin and Revelle (after an interim Scripps directorship by Eckart), and together with Ewing these three men dominated the post-war era in the United States (Figure 3). Together they set the national priorities for years to come. The U.S. oceanography budget was upped by more than an order of magnitude. There has not been such a determined leadership since.

Figure 2. Portrait of Harald Sverdrup by Paul Williams, c. 1946. 
(a)

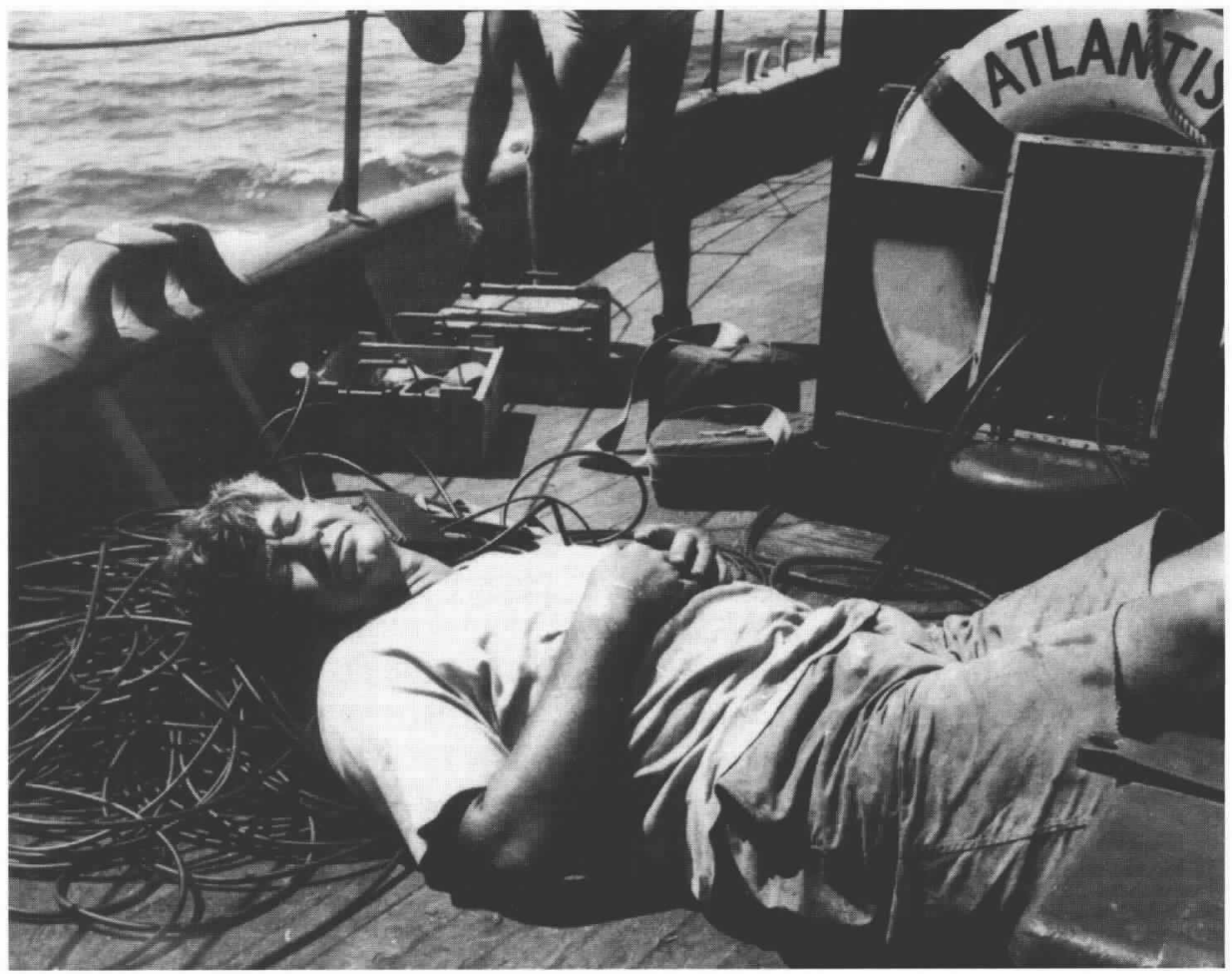

(b)

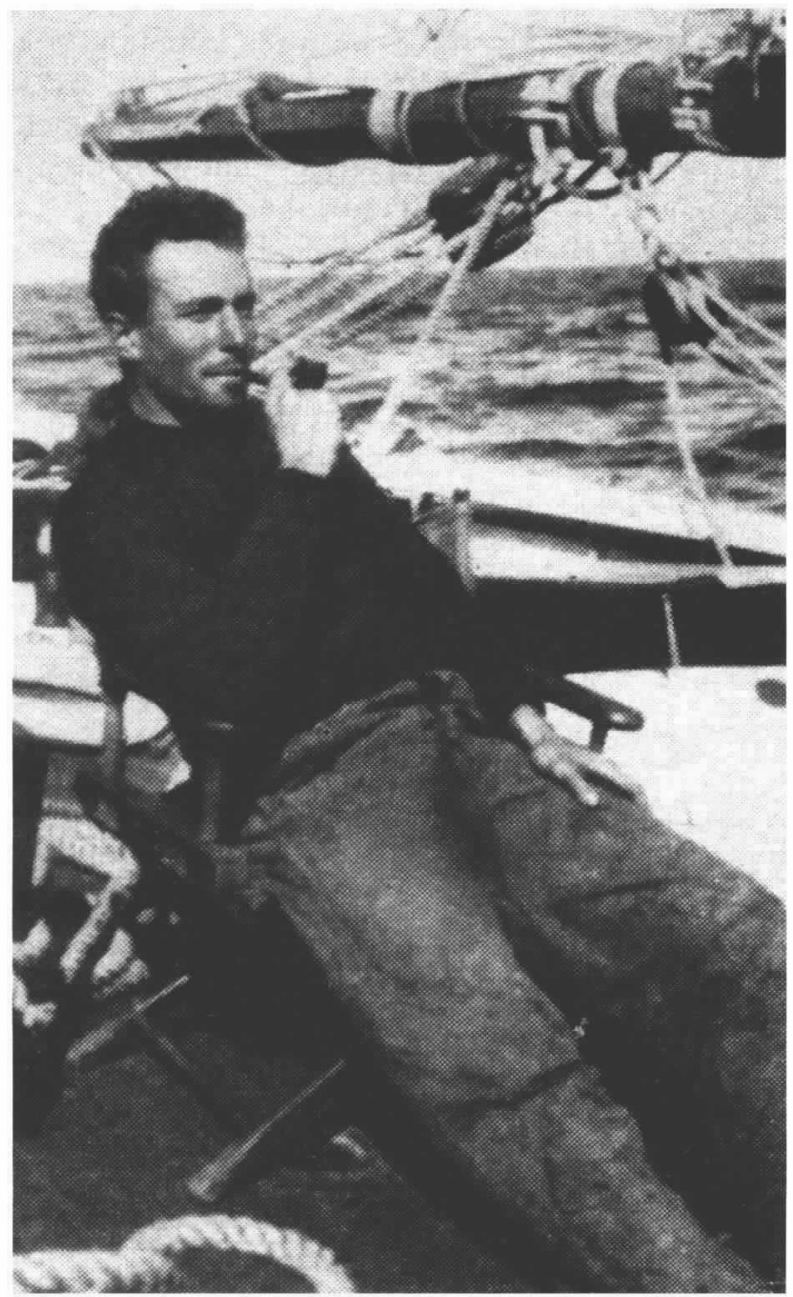

(c)

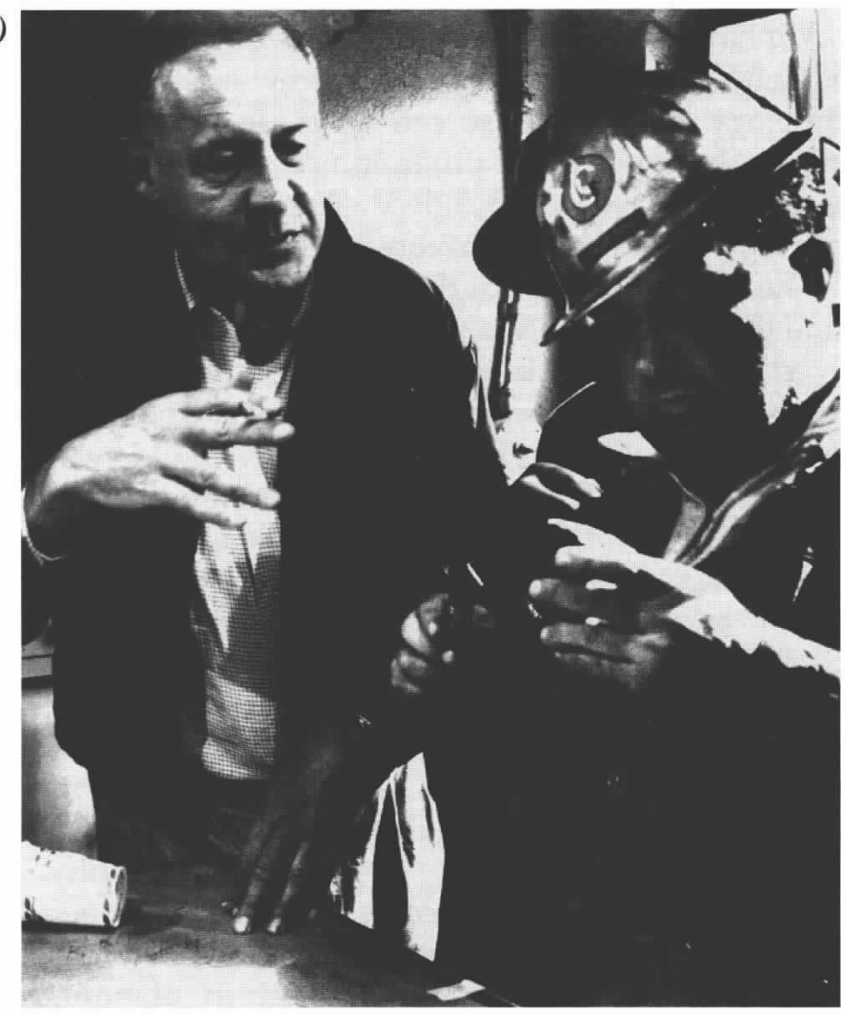

Figure 3. a) Maurice Ewing aboard the $R / V$ Atlantis. b) Columbus Iselin aboard the $R / V$ Atlantis in 1929. c) Roger Revelle and roughneck on the CUSS I during the 1961 Mohole feasibility study (photo by Fritz Goro for LIFE Magazine). 
Maurice Ewing had an obsession with collecting data at sea, and we have all profited enormously. He played a major role in developing seismic, magnetic and gravity methods for use at sea. He discovered the SOFAR sound channel. Columbus Iselin had an innate sense of the ocean environment. He was Captain of the R.V. Atlantis on her Maiden Voyage to Woods Hole. He had a distrust of formal training in oceanography; among his most successful appointments were Alan Woodcock, a sailor on the Atlantis, and Fritz Fuglister, an artist. Roger Revelle is best known for having taken the Scripps Institution to sea. He and Suess did the pioneering work on carbon dioxide and climate modifications. Science featured the Albatross Award (initiated by three ONR project officers) with a caged bird on its front cover and a quote from Roger: "Oceanographers have more fun" (Figure 4). Our discipline had arrived.

Henry Stommel (Figure 5) was the leading figure in physical oceanography; early on he developed an intuition for the conservation of potential vorticity, with far-reaching consequences.

\section{Closing Remarks}

Our world has changed since the evening in the year 1900 when young Ekman solved the spiral equation. One is tempted to wrap the thousands of things that have happened into a single package. My package has a rather dreary label: SAMPLING. I suggest that the key development between the century of the Challenger and the late $20^{\text {th }}$ century is: adequate sampling. The key contribution of the CTD (Conductivity-TemperatureDepth sensor) was not more precision than the Nansen cast (in fact the precision initially dropped from 0.01 to $0.1^{\circ} \mathrm{C}$ ); it was going from discretely sampled to continuous vertical profiling. The most important satellite contribution is not the instrument packages (remarkable as they are) but the ability to sample the global ocean and to sample it adequately in $x, y$-space (two different things). But sampling in time at about ten day intervals (determined by orbital dynamics) is not so good and has led to some horrendous aliasing problems. A key contribution of computers and the associated transition from analogue to digital recording was to impose on a new generation of oceanographers something that the previous generation had not learned: the discipline of adequate sampling.

Beware of ignoring the Sampling Theorem; it is unforgiving. Dozens of low-frequency phenomena given birth in the $20^{\text {th }}$ century are the illegitimate offspring of an aliased liaison. Even the uncanny intuition of a Fritz Fuglister for the behavior of the Gulf Stream was not able to overcome the inadequate sampling of his time?

In 1954, Stommel privately printed a pamphlet entitled: "Why do our ideas about ocean circulation have such a peculiarly dream-like quality?" Dreamlike,
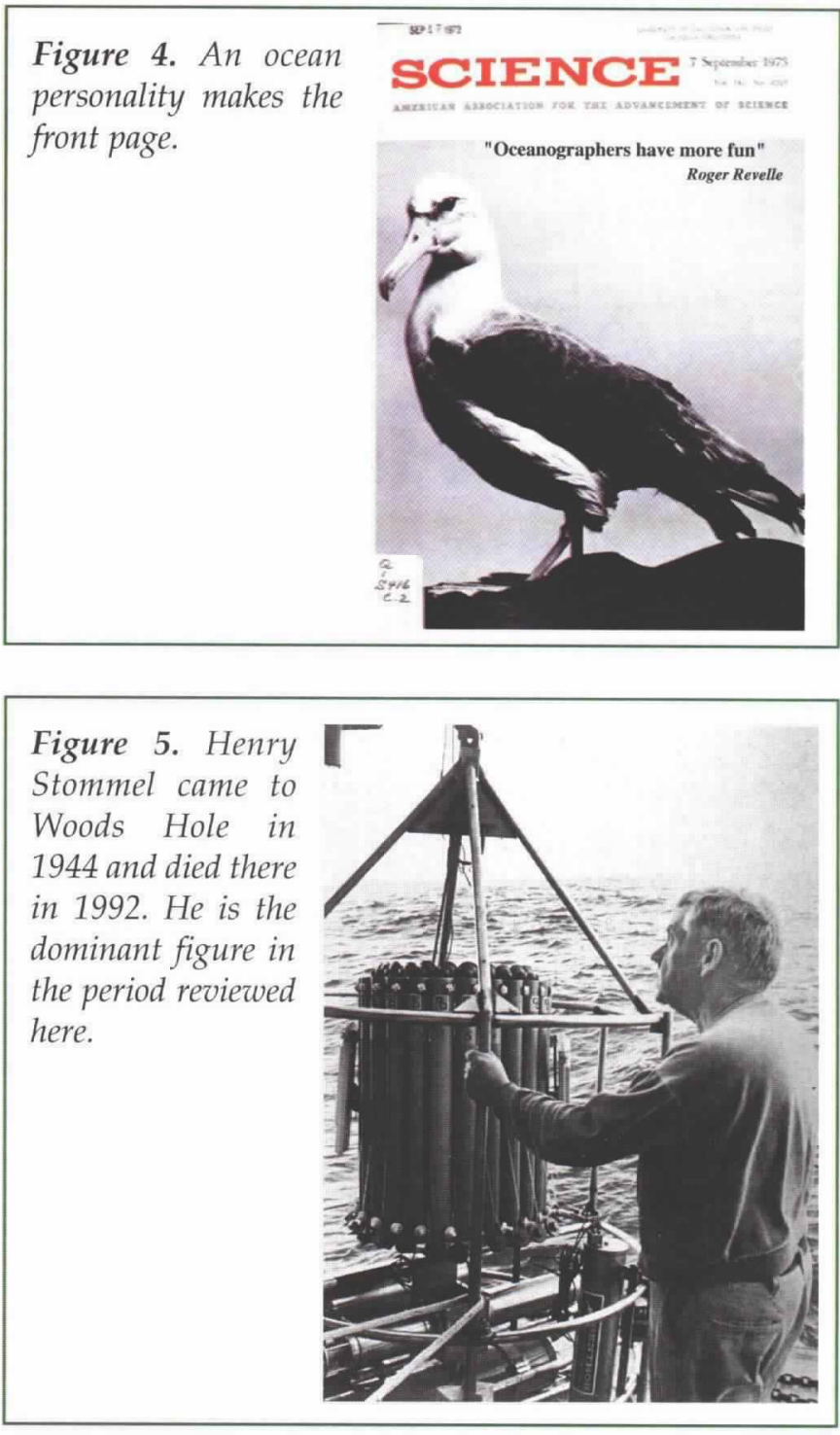

indeed. An ocean with currents of $10 \pm 1 \mathrm{~cm} / \mathrm{s}$ (as we then thought) is far different from an ocean with $1 \pm 10$ $\mathrm{cm} / \mathrm{s}$. My teacher Harald Sverdrup considered it one of the chief functions of physical oceanographers to provide biologists the background information for studying life in the sea. I am afraid that our concepts were too dream-like to provide useful guidance.

Today we provide information that is useful (sometimes). This is a mixed blessing. Our curiosity-driven community of fellow adventurers has now been joined by result-oriented engineers and profit-oriented students. We enter the prediction arena at a high price; our failures (and there have been many) will now be publicly vented. This is an inevitable result of going from fun-loving adventure (Figure 4) to public service. We plead to the National Science Foundation and to funding bodies around the globe not to turn their backs on "curiosities" and high-risk ventures, and to retain a tolerance for failure. 